\title{
O que Dizem os Alunos sobre a Avaliação Escolar
}

\author{
BEATRIZ PEDRO CORTESE \\ Ex-Coordenadora Pedagógica e Orientadora Educacional do $1^{\circ}$ Ciclo do \\ Ensino Fundamental da Escola de Aplicação da \\ Faculdade de Educação da Universidade de São Paulo \\ biacortese@uol.com.br
}

\begin{abstract}
Resumo
"O que dizem os aluno sobre avaliação?" Com a finalidade de responder a esta pergunta, em minha pesquisa de mestrado entrevistei alunos do $4^{\circ}$ ano do Ensino Fundamental. Para analisar os sentidos por eles produzidos, utilizei concepções desenvolvidas por estudiosos do cotidiano escolar, entre eles José Mario Azanha e Marli André. Além disso, as idéias de linguagem e de discurso apresentadas por Mikhail Bakhtin e revista por Mary Jane Spink foram essenciais para o desvelamento dos discursos infantis. Neste artigo, os sentidos produzidos pelos alunos estão divididos em sete blocos: no primeiro, encontram-se idéias a respeito da palavra avaliação. Ponderações a respeito de quando e como as crianças percebem a avaliação das educadoras estão no segundo bloco. Em que momentos e quem os alunos sentem-se autorizados a avaliar é a temática do terceiro, e o quarto bloco baseia-se nas reflexões das crianças sobre a objetividade e a neutralidade das práticas avaliativas. $\mathrm{O}$ quinto bloco refere-se às razões que, supostamente, movem as preferências das professoras por determinados alunos. As representações dos entrevistados a respeito do impacto da avaliação escolar para as relações presentes e futuras estão no sexto bloco. No sétimo, vemos como os alunos justificam o próprio desempenho e o de seus colegas.
\end{abstract}

Palavras-chave: produção de sentidos, avaliação, relação professor-aluno.

\begin{abstract}
Resumen
"¿Qué dicen los alumnos sobre evaluación?" Con la finalidad de responder a esta pregunta, en mi investigación de master entrevisté alumnos del $4^{\circ}$ año de la Enseñanza Básica. Para analizar los sentidos por ellos producidos, utilicé concepciones desenvueltas por estudiosos del cotidiano escolar, entre ellos José Mario Azanha y Marli André. Además, las ideas de lenguaje y de discurso presentadas por Mikhail Bakhtin y revisadas por Mary Jane Spink fueron esenciales para desvelar los discursos infantiles. En este artículo, los sentidos producidos por los alumnos están divididos en siete bloques: en el primero, se encuentran ideas sobre la palabra evaluación. Ponderaciones sobre cuándo y cómo los niños perciben la evaluación de las educadoras están en el segundo bloque. En qué momentos y a quién los alumnos se sienten autorizados a evaluar es el tema del tercero, y el cuarto bloque se basa en las reflexiones de los niños sobre la objetividad y la neutralidad de las prácticas de evaluación. El quinto bloque se refiere a las razones que, supuestamente, mueven las preferencias de las profesoras por determinados alumnos. Las representaciones de los entrevistados sobre el impacto de la evaluación escolar en las relaciones presentes y futuras
\end{abstract}


están en el sexto bloque. En el séptimo, vemos como los alumnos justifican su propio desempeño y el de sus compañeros.

Palabras-clave: producción de sentidos, evaluación, relación profesor-alumno.

\begin{abstract}
"What do students say about assessment?" Aiming at answering this question, in my master's research I interviewed students in the $4^{\text {th }}$ year of Elementary School. In order to analyze the meanings produced by them, I made use of notions developed by specialists in school routine, among them José Mário Azanha and Marli André. Also, the ideas about language and discourse presented by Mikhail Bakhtin and reviewed by Mary Jane Spink were essential to unveil the children's discourse. In this article, the meanings produced by students are divided into seven parts: the first part deals with ideas about word evaluation. Considerations on how and when children perceive educator's assessment are found in the second part. At what moments students feel they are allowed to make assessments, and who they are allowed to assess is the topic of the third part, and the fourth is based on the children's reflections on the objectivity and neutrality of assessment practices. The fifth part refers to the reasons that supposedly guide teachers' preference for certain students. The interviewees' representations of the impact of school assessment on current and future relationships are found in the sixth part. In the seventh, we see how students justify their own performance and that of their peers.
\end{abstract}

Key words: production of meanings, evaluation, student-teacher relationship. 


\section{INTRODUÇÃO}

Até que ponto os alunos conseguem perceber que a avaliação escolar é um componente importante para a construção do valor de si? Eles reconhecem seus colegas, professores e pais como interlocutores? Sentemse autorizados a também avaliar?

Lecionei durante alguns anos no Ensino Fundamental e atualmente sou coordenadora pedagógica e orientadora educacional do $1^{\circ}$ ciclo de uma escola particular. Durante meu percurso profissional, pude perceber que a avaliação escolar determina as relações que se estabelecem na escola, ao mesmo tempo em que é determinada por elas. Meu interesse em compreender como os alunos produzem significados sobre os processos avaliativos a que são submetidos transformou-se em uma pesquisa de mestrado que resultou neste artigo.

As questões apresentadas no primeiro parágrafo orientaram a pesquisa, que foi dividida em duas partes: na primeira encontra-se o relato de situações cotidianas, nas quais pais, professores e alunos protagonizam conflitos que envolvem a avaliação. $\mathrm{Na}$ segunda, alunos do $4^{\circ}$ ano do Ensino Fundamental produzem sentidos sobre a avaliação escolar em entrevistas coletivas e é isso o que será aqui apresentado.

As conclusões a que cheguei na primeira parte do trabalho nortearam a organização das entrevistas, pois auxiliaram na determinação dos informantes mais adequados e na elaboração do roteiro; além disso, durante todo o processo meu olhar sobre o tema esteve impregnado das reflexões feitas anteriormente. Entre essas conclusões, duas são essenciais para a compreensão do processo de entrevistas.

A construção do valor de si relaciona-se a alguns fatores: às expectativas pessoais, às representações que a própria pessoa constrói sobre os outros, às representações que os outros constroem a respeito da pessoa em questão e aos sucessos e fracassos objetivamente constatados ( $\mathrm{La}$ Taille, 2002). Se considerarmos a construção dessas representações como valorativas - porque impregnadas de juízos de valor - e nos lembrarmos que a aprendizagem dos conteúdos escolares é socialmente valorizada, podemos concluir que esta aprendizagem integra as expectativas pessoais. Além disso, os resultados de desempenho escolar podem ser compreendidos como sucessos e fracassos objetivamente constatados. ${ }^{1}$ Dessa forma, o desempenho escolar é um dos fatores que influenciam a construção do valor de si. Alunos com baixa auto-estima, cujo valor de si é construído baseado em características por eles consideradas negativas, têm

${ }^{1}$ No decorrer deste texto, essa afirmação será revista indiretamente. 
muita dificuldade para a aprendizagem dos conteúdos escolares, o que acaba por confirmar a construção de um valor de si negativo.

A segunda conclusão relaciona-se à primeira: uma vez que há conexão entre aprendizagem de conteúdos escolares e construção do valor de si, parece-me essencial conhecer como as crianças percebem as influências das relações escolares - no caso, originadas pelas práticas avaliativas - para a construção das representações de si. Se levarmos em conta a relação entre a aprendizagem dos conteúdos escolares e a construção do valor de si, e concebermos os sentidos produzidos como um nível de conhecimento, como algo intermediário, que ocupa o intervalo, as lacunas, entre o sujeito e o objeto, poderemos considerar que o desempenho escolar determina as percepções sobre avaliação.

Para analisar os dados coletados com as entrevistas, considerei-as como práticas discursivas; assim, antes de descrever a escola, julgo ser pertinente definir o que chamei de prática discursiva. Para melhor explicitar essa idéia, recorro a Mary Jane Spink e a seus colaboradores: se entendermos que o mundo só pode ser conhecido por artefatos sociais produtos de intercâmbios entre pessoas - consideraremos as descrições e explicações sobre ele como formas de ação social entremeadas por atividades humanas. Assim, só conseguimos apreender os sentidos e objetos do mundo a partir de nossas experiências, de nosso conhecimento.

O conhecimento, por sua vez, é algo que as pessoas constroem, portanto, está social e historicamente situado. Por outro lado, o pensamento é uma construção individual determinada por características sóciohistóricas. $\mathrm{O}$ pensamento é um processo que se dá na interface entre o cérebro e a sociedade. Enquanto o cérebro possibilita que o pensamento aconteça, a sociedade oferece as ferramentas necessárias. Uma das principais ferramentas utilizadas pelo cérebro para a construção do pensamento é a linguagem (T. Ibañez, 1994, apud Spink, 2000).

Atualmente, muitos pesquisadores (inclusive Spink) utilizam-se de uma concepção de linguagem baseada na que foi desenvolvida por Mikhail Bakhtin. Segundo esse autor, a linguagem é um fenômeno social da interação, é o lugar do conflito social. Nessa perspectiva, seu princípio fundador é a interação entre interlocutores. Nada é falado no vazio, mas sim numa situação histórica e social concreta, no momento e no lugar do enunciado.

O enunciado, por sua vez, é a unidade real da comunicação verbal, ele é produto da interação entre indivíduos socialmente organizados, ou seja, é produto da interação de interlocutores. Qualquer enunciação, por mais significativa e completa que seja, constitui apenas uma fração da corrente de comunicação verbal ininterrupta; cada enunciado é um elo da 
cadeia muito complexa de enunciados. $\mathrm{O}$ enunciado não é uma unidade convencional, mas uma unidade real, estritamente delimitada pela alternância dos sujeitos falantes, pela transferência da palavra ao outro.

As fronteiras do enunciado concreto, compreendido como a unidade da comunicação verbal, são determinadas pela alternância dos sujeitos falantes, dos interlocutores. Nenhum enunciado comporta um começo absoluto e um fim absoluto; antes de seu início há os enunciados dos outros, depois de seu fim há os enunciados respostas dos outros.

Essa concepção remete-nos à idéia de dialogismo, cuja compreensão está intrinsecamente relacionada à concepção de diálogo. Essa palavra deve ser entendida num sentido amplo e não apenas como comunicação em voz alta de pessoas fisicamente próximas, mas como toda comunicação verbal, seja ela qual for.

O princípio dialógico está baseado tanto no diálogo entre interlocutores quanto no diálogo entre discursos. Toda a parte verbal do nosso comportamento (quer se trate de linguagem interior ou exterior) não pode ser atribuída a um sujeito individual considerado isoladamente, pois a interação verbal está no centro das relações sociais. As práticas discursivas são formas de interação verbal que incorporam discursos de outros e outros discursos, a partir dos quais forma-se um novo discurso.

O dialogismo diz respeito ao permanente diálogo, nem sempre simétrico e harmonioso, existente entre diferentes discursos que configuram uma comunidade, uma cultura, uma sociedade. Em outras palavras, as relações que se estabelecem entre o eu e o outro nos processos discursivos instaurados historicamente pelos sujeitos - que se instauram e são instaurados por esses discursos - é o que chamamos de princípio dialógico da linguagem.

E é essa concepção de dialogismo que define um texto ou um discurso como um tecido de muitas vozes - ou de muitos textos ou discursos - que se cruzam, se completam, respondem uns aos outros ou polemizam entre si no interior do texto/discurso. $O$ sentido do texto/discurso e a significação das palavras dependem da relação entre sujeitos; constroem-se na produção e na interpretação dos textos/discursos.

A concepção de dialogismo de Mikhail Bakhtin se fundamenta na negação da possibilidade de conhecer o sujeito fora do discurso que ele produz, já que só pode ser apreendido como uma propriedade das vozes que ele (sujeito) enuncia. Ou seja, os sujeitos instauram-se e são instaurados por discursos, que partem das relações que se estabelecem entre o eu e o outro, nos processos discursivos formados historicamente pelos próprios sujeitos. 
Mary Jane Spink parte da concepção de linguagem apresentada por Bakhtin e a amplia, propondo a revisão de alguns conceitos. Entre outras coisas, a autora define como práticas discursivas os momentos ativos do uso da linguagem nos quais convivem tanto as ordens quanto a diversidade - equivalendo ao que Bakhtin chamou de discurso. Trata-se da linguagem em ação, são as maneiras a partir das quais as pessoas produzem sentidos e posicionam-se em suas relações cotidianas.

Segundo Bakhtin, no contexto dialógico não há primeira ou última palavra; assim, não há limites para a produção de sentidos, pois eles se estendem do passado sem fronteiras ao futuro infinito; dessa forma, mesmo os sentidos mais antigos podem ser resignificados. Então, para compreendermos os sentidos de determinadas práticas discursivas é preciso trabalhar o tempo discursivo na interface de três tempos históricos: o tempo longo, o tempo vivido e o tempo curto.

Os conteúdos culturais definidos ao longo da história da civilização marcam o tempo longo, que está no domínio da construção social. Nesse tempo histórico, podemos apreender os repertórios disponíveis em determinada época/lugar que constituem muitas das vozes que povoam nossos enunciados, mesmo que não tenhamos clareza de suas origens.

As experiências individuais correspondem ao tempo vivido, e é nesse nível que ocorre a aprendizagem das linguagens sociais. Trata-se de um conjunto de esquemas apreendidos desde a infância e permanentemente atualizados ao longo da trajetória social da pessoa. É o tempo da memória traduzida em afetos, e é por esse ângulo que enraizamos nossas narrativas pessoais e nossa identidade.

O tempo das interações sociais face a face, em que os interlocutores comunicam-se diretamente, é o tempo curto. Ele é pautado pela dialogia e pela concorrência de múltiplos repertórios, utilizados para dar sentido às experiências humanas. É nesse tempo que podemos compreender a dinâmica da produção de sentidos, é o tempo do acontecimento, da interanimação dialógica. Para compreendermos o modo como os sentidos circulam na sociedade, e especificamente na escola, é necessário considerar a interface desses três tempos, porque é nela que se processa a produção de sentidos.

Os dados coletados com as entrevistas tornaram-se significativos quando os compreendi como práticas discursivas. Assim, as entrevistas foram consideradas formas de ação e de interação. Essa interação aconteceu num contexto específico - alunos conversando com a coordenadora da escola, em uma sala de aula, a respeito da avaliação escolar - numa relação negociada, com seus objetivos explicitados antes do momento das entrevistas. 
Durante as entrevistas não foram raros os momentos em que os alunos significaram e resignificaram os sentidos por eles produzidos. Então, para analisar as entrevistas, foi preciso desvelar, nas práticas discursivas dos alunos, vozes pertencentes aos três tempos históricos: longo, vivido e curto, e a partir daí procurar permanências e contradições entre as práticas discursivas de todo o grupo e de cada um dos participantes.

Tanto o momento da entrevista quanto o processo de interpretação dos dados coletados são espaços de produção de sentidos. Segundo Spink, muitas são as ações que compõem um percurso de pesquisa: posicionar-se, buscar novas informações, priorizar e selecionar dados; todas elas conseqüências dos sentidos que produzimos durante a interpretação.

Como em muitas outras instâncias de nossa vida, ao pesquisar procuramos entender os eventos de acordo com as categorias, hipóteses e informações contextuais que conhecemos (Spink, 2000), e a interpretação emerge como um elemento intrínseco desse processo. Assim, praticamente não há distinção entre o momento de levantamento das informações e o da interpretação, pois durante todo o tempo estamos interpretando. Por outro lado, ao finalizar a pesquisa é preciso revelar os sentidos resultantes do percurso vivido, apresentando cada passo que foi dado para assegurar o rigor necessário - entendido aqui como a objetividade possível numa situação subjetiva. Nesse sentido, nos próximos parágrafos descreverei brevemente a elaboração do roteiro, a condução das entrevistas e a organização dos dados coletados.

A escola na qual a pesquisa foi realizada está organizada em três ciclos, com progressão continuada no interior de cada um deles: o primeiro compreende do primeiro ao quarto ano do Ensino Fundamental, o segundo comporta do quinto ao oitavo ano do Ensino Fundamental, e o Ensino Médio compõe um único ciclo de três anos. Atualmente, os educadores utilizam três conceitos para representar as sínteses de desempenho escolar de seus alunos: NS ou Não Satisfatório; S ou Satisfatório; PS ou Plenamente Satisfatório.

Há muitos anos, a escola optou por especializar a atuação das professoras polivalentes para o $3^{\circ}$ e o $4^{\circ}$ ano do $1^{\circ}$ Ciclo do Ensino Fundamental. Quando a pesquisa foi realizada, Margarida trabalhava com Língua Portuguesa, História e Geografia nas duas classes do $4^{\circ}$ ano, e Carolina ensinava Matemática e Ciências, também para as duas turmas.

Um dos objetivos das entrevistas era averiguar a percepção dos alunos sobre o efeito das avaliações (seja em seu sentido mais restrito, de conceito, seja em contextos mais amplos, de relações interpessoais) para a construção do valor de si; desse modo, era preciso fazer agrupamentos os 
mais homogêneos possíveis, no que se refere ao desempenho dos estudantes. Para isso, solicitei às professoras que dividissem os alunos do $4^{\circ}$ ano em três grupos, de acordo com o desempenho escolar.

Então, entrevistei seis grupos de crianças, nos quais havia de oito a doze alunos (fiz três entrevistas com cada classe do $4^{\circ}$ ano). Cada um dos agrupamentos (das duas classes) recebeu uma nomeação para facilitar tanto a apresentação quanto a análise dos dados: Grupo 1 refere-se a alunos com bom desempenho escolar, que costumam apresentar PS (plenamente satisfatório) como conceito obtido nas provas. Os alunos do Grupo 2 apresentam desempenho considerado satisfatório e a maioria dos conceitos por eles obtidos é $S$ (satisfatório). O Grupo 3 representa alunos com dificuldade para aprendizagem dos conteúdos escolares, cujo conceito predominante é NS (não satisfatório).

$\mathrm{O}$ roteiro das entrevistas foi elaborado em três versões, uma para cada Grupo (1, 2 e 3), o que foi necessário por causa das questões diretas sobre o desempenho escolar ou sobre como os alunos se sentem em relação ao processo de avaliação. Os roteiros foram organizados em três grandes temas: como entendem e definem a palavra avaliação e como a percebem no cotidiano escolar; como justificam as diferenças de seus desempenhos; quais as conseqüências - para os alunos - da avaliação escolar.

Ao conduzir as entrevistas, procurei problematizar as respostas das crianças de modo a levá-las a apresentar a própria opinião e não apenas responder o que supostamente seria mais adequado. Numa entrevista coletiva, as vozes dos locutores presentes misturam-se entre si e com as vozes internalizadas pelos participantes, assim, não se tem clareza do que é individual. No entanto, é possível encontrar especificidades e contradições nas práticas discursivas de cada um dos grupos e de cada uma das crianças.

Ao final das entrevistas, e com todas as fitas transcritas, elaborei uma tabela com todos os diálogos; nas linhas coloquei as perguntas que fiz aos alunos e nas colunas as respostas. Como cada entrevista aconteceu num ritmo próprio, a ordem em que as perguntas foram feitas também variou, por isso - na tabela - os diálogos não estão na ordem em que ocorreram, mas conforme as perguntas geradoras de cada grupo de respostas.

Com essa tabela pronta, foi possível concluir que o material coletado é bastante rico e sugere inúmeras reflexões. Porém, houve a necessidade de selecionar os dados relevantes para este trabalho e omitir as digressões e associações livres, inevitáveis em situações de entrevista. Todavia, vale salientar que a quantidade de dados desprezados - menos de dez por cento - foi relativamente pequena se levarmos em conta a idade dos alunos e o tempo de conversa - por volta de uma hora e meia. 
Depois de algumas leituras da tabela, percebi a possibilidade de classificar as respostas das crianças em sete blocos. No primeiro, encontram-se idéias a respeito da palavra avaliação e suas concepções sobre avaliação escolar. Ponderações a respeito de quando e como as crianças percebem a avaliação das educadoras estão no segundo bloco. Em que momentos e quem os alunos sentem-se autorizados a avaliar é a temática do terceiro bloco, e o quarto baseia-se nas reflexões das crianças sobre a objetividade e a neutralidade das práticas avaliativas. O quinto bloco refere-se às razões que, supostamente, movem as preferências das professoras por determinados alunos. As representações dos entrevistados a respeito do impacto da avaliação escolar para as relações presentes e futuras estão no sexto bloco. No sétimo bloco, vemos como os alunos justificam o próprio desempenho e o de seus colegas.

\section{O QUE É AVALIAÇÃO; O QUE É AVALIÁVEL?}

Em relação à conceituação de avaliação escolar, o discurso dos alunos trouxe elementos para refletirmos sobre três questões principais: primeiras impressões sobre a palavra avaliação; situações extra-escolares em que encontramos avaliações; e o que e quem são passíveis de avaliação.

"Qual a primeira coisa que vocês lembram ao ouvir a palavra avaliação?" As respostas a esta pergunta foram praticamente unânimes: prova escrita. No Grupo 2 (satisfatório) uma das crianças ampliou essa relação dizendo lembrar-se de estudar e da idéia de repetir de ano. Alguns alunos do Grupo 3 (não satisfatório) enxergam certa afinidade entre avaliação e esperteza/inteligência, e a vêem como uma forma de controle, associandoa ao pensamento. Uma das crianças disse que avaliar seria para a professora saber como a gente está pensando... se está bem, pensando bem.

Quando lhes perguntei se conseguiam identificar a existência de avaliação fora da escola, os entrevistados do Grupo 1 (plenamente satisfatório) reconheceram-na em locais públicos como restaurantes, cinemas, shoppings e até nas ruas, e associaram o avaliador às pessoas responsáveis por manter a ordem como guardas, policiais e seguranças. Esses personagens não apareceram nas práticas discursivas dos alunos do Grupo 2, que percebem a existência de avaliação nas ruas, mas só a relacionaram com multas de trânsito. Alunos desses dois Grupos enxergam a avaliação nas famílias e em diferentes instituições.

Para os entrevistados do Grupo 3 a escola, outros locais de ensino formal e o emprego dos pais são os únicos espaços em que a avaliação está presente; na família ela só é vista como conseqüência do desempenho 
escolar. Foi preciso voltar a esse tema, em momento posterior da entrevista, para que as crianças identificassem outros critérios para a avaliação que acontece nas famílias.

Os diálogos estabelecidos no Grupo 3 levam-me a inferir duas razões para essa dificuldade: por um lado, percebe-se a intenção desses alunos em responder adequadamente, em atender às (supostas) expectativas da coordenadora da escola, como se o fato de estarem conversando comigo os impedisse de fazer relações com outras instâncias de suas vidas. Por outro, seus sentimentos em relação à avaliação escolar adquirem uma dimensão tão grande e, muitas vezes, tão pesada, que os impedem de perceber sua existência em outros lugares, pois a densidade não seria a mesma.

A maioria dos alunos relaciona a palavra avaliar à explicitação de idéias e de opiniões. Poucas crianças conseguem perceber que é possível fazer uma avaliação e não expressá-la; além disso, só são passíveis de avaliação pessoas ou coisas que exigem mudanças, revisões e reformas, como nos mostram alguns alunos do Grupo 1.

\section{Grupo 1}

Pesquisadora: Vocês avaliam a Carol?

Vítor: A Carol não tem muito o que mudar, está bom assim...

Pesquisadora: E para avaliar é preciso, sempre, ter o que mudar?

Daniel: Eu acho a Carol normal.

Pesquisadora: Você não fez uma avaliação para achá-la normal?

Daniel: Não... ela é legal, ela já é mais calma...

Segundo os entrevistados, na avaliação está implícita a necessidade de alterações no objeto ou na pessoa avaliada. Se tudo o que é avaliado exige mudança, será que os alunos, que sempre são avaliados, nunca estão bons?

\section{O OLHAR DAS PROFESSORAS}

Mesmo relacionando a palavra avaliação à prova escrita, os alunos acreditam que estão sendo avaliados o tempo todo: as professoras observam suas atitudes e sempre estão olhando, registrando, comentando. Os alunos percebem esse movimento nas duas professoras; contudo, o caráter controlador e observador da avaliação é enfatizado pela prática discursiva da professora Margarida (Língua Portuguesa, História e Geografia), que costuma afirmar que os avalia ininterruptamente, e essa 
percepção é comum a todos os Grupos. Poucos alunos, e sempre os do Grupo 1, conseguem criticar isso, como fez Vítor: ...não faz sentido... para Margarida até ir ao banheiro vale nota...

As crianças desenvolveram estratégias para observar suas professoras e identificar exatamente o momento em que estão sendo analisadas. Quando lhes perguntei se percebiam o momento exato em que as professoras avaliavam, muitas crianças identificaram o olhar aliado a outros gestos e atitudes.

\section{Grupo 3}

Pesquisadora: Tem algum momento em que vocês olham para elas e falam: ela está avaliando?

Fernanda: Sim, quando ela fica de olho assim [fechou os olhos, observando com "rabo de olho"].

Pesquisadora: Ela é a Margarida, a Carolina ou as duas?

Fernanda: As duas.

Edu: A Margarida, mais a Margarida. A Margarida é como se fosse dar uma prova, aquele olhar de "Ô, mocinho!"

Pedro: Quando ela olha e vem vindo...

De acordo com esses alunos do Grupo 3 (NS), as duas professoras utilizam o olhar para comunicar-se com eles, não se trata de uma característica exclusiva de Margarida; entretanto, nela isso torna-se quase caricatural, como identificou Edu ao qualificar o olhar dessa professora e relacioná-lo a uma expressão comumente utilizada por ela, quando quer chamar a atenção de um aluno: "Ô, mocinho".

É provável que essa relação tão arraigada entre a idéia de controle e a de avaliação escolar seja conseqüência direta das práticas desenvolvidas pelos professores. Vimos que os alunos, de todos os Grupos, sentem-se observados continuamente; vimos também que a sustentação desse discurso e dessa prática, por parte dos professores, relaciona-se à manutenção da ordem e do controle na sala de aula.

\section{ALUNOS PODEM AVALIAR?}

Avaliações fazem parte das relações entre pessoas; assim, poderíamos esperar que os alunos percebessem que não apenas são avaliados, como também exercem a função de avaliadores. As respostas das crianças confirmam que a acuidade para compreender a reciprocidade como uma característica da avaliação é conseqüência do valor de si, 
construído pelos alunos com base em seus desempenhos escolares. Em outras palavras: crianças bem-avaliadas sentem-se mais autorizadas a também avaliar seus avaliadores.

Quando perguntei aos alunos se eles avaliam alguém, os membros do Grupo 1 responderam espontaneamente que avaliam irmãos, amigos, pais, professores e também fazem auto-avaliações. Os alunos do Grupo 2 responderam a essa pergunta de forma ambivalente: num primeiro momento não disseram avaliar as professoras, todavia, concordaram prontamente com a idéia. No Grupo 3 (NS) os alunos informaram que avaliam irmãos, colegas a até animais de estimação, como cachorro e papagaio; um único aluno disse que avaliava a mãe e o tio.

Muitos alunos do Grupo 3 tiveram dificuldade em confirmar que avaliam os professores: conversamos sobre o que estaria contemplado na palavra avaliação e, como coordenadora da escola, precisei autorizá-los, claramente, a tecer considerações a respeito de educadores da instituição. Esse movimento não foi necessário nos Grupos 1 e 2, cujo contexto permitiu-lhes explicitar idéias, emoções e sentimentos. Aparentemente, essas crianças sentem-se autorizadas a avaliar apenas pessoas hierarquicamente inferiores ou similares a eles e não figuras de autoridade, como pais e professores.

\section{Grupo 3}

Pesquisadora: O Tiago falou que as crianças avaliam, vocês concordam? Vários: Não!

Ana: Só em trabalho em grupo... [...]

Pesquisadora: E em outras situações, aluno avalia?

Vários: Não! [...]

Pesquisadora: Pensando que avaliar é ter opinião sobre as coisas, vocês avaliam professor?

Vários: Não!

Gabi: Você não fala assim: Carolina, você tirou NS...

Todas as crianças tecem considerações sobre seus professores; entretanto, a dificuldade dos alunos do Grupo 3 está em sentirem-se autorizados a admitir que isso acontece. Aparentemente, não se trata apenas de uma relutância em falar sobre o fato na entrevista, mas também em perceber que esse é um pensamento - e até um sentimento - legítimo, indissociável das relações humanas e que, por isso, não precisa ser encoberto, escondido. É como se eles não tivessem o direito a esse sentimento e, assim, sua existência não pudesse ser desvelada. 
Depois de conversarmos sobre as possibilidades de alunos avaliarem professores, perguntei a eles o que diferencia a avaliação que os professores fazem dos alunos da avaliação que estes fazem daqueles. Para a maioria dos entrevistados, os educadores avaliam o esforço do aluno para apresentar bom desempenho escolar, enquanto eles avaliam o comportamento do professor, seu jeito de atuar e de planejar as aulas. Por um lado, as professoras utilizam recursos sistematizados e até institucionalizados; por outro, o tipo de conseqüência da avaliação é bastante diferente. Um aluno mencionou os registros da professora como um instrumento de avaliação não utilizado pelos alunos. Vivi (Grupo 2) esclareceu que a avaliação das professoras traz conseqüências para a vida dos estudantes, e a que é feita por eles não vale nada.

Ao observar as descrições dos alunos a respeito das avaliações que fazem de seus pais e professores, pode-se notar que, na maioria das vezes, essa avaliação acontece como uma forma de eles se defenderem dos olhares judicativos de outras pessoas, ou seja, avaliam os outros por temerem as avaliações alheias.

\section{Grupo 1}

Daniel: O que eu não gosto da minha mãe é quando ela passa muita maquiagem e quando a gente está no farol vermelho ela liga o rádio e começa a dançar... as pessoas do lado olham assim... ela põe música brega, é horrível! ... acho que ela faz só para me provocar... [...]

Vítor: Quando meu pai vem me trazer na escola ele leva minha mochila até a entrada e eu não gosto disso porque meus amigos ficam falando...

Vítor não gosta que seu pai carregue a mochila até a porta da escola. $\mathrm{O}$ pai carregar a mochila na garagem de casa provavelmente não o incomoda, pois o que ele teme é a avaliação dos colegas. Nesse caso, é a iminência do sentimento de vergonha o principal critério para a avaliação que as crianças fazem de seus pais, o que também é revelado por Daniel; sua mãe dança e canta no carro para provocá-lo, envergonhá-lo.

No trecho a seguir, alguns alunos do Grupo 2 demonstram que avaliam a professora por temerem as conseqüências da avaliação dela.

\section{Grupo 2}

Julia: Dá um pouco de raiva porque o professor escreve tudo na lousa, vai lá e apaga.

Luciana: Aí, quando eles vão ver o caderno, está tudo, tudo rabiscado, porque eles mudaram a lousa, a gente não pode justificar... 
Pesquisadora: E não pode explicar para a professora?

Gui: Ela escreve lá; tan, tan, tan... aí ela apaga... E todo mundo, apressado, quer acabar logo, já copiou, aí: Ahhh!

Taís: Aí ela pergunta: "Que caca é essa no seu caderno?"

Pesquisadora: E quando ela pergunta, "que caca é essa", não dá para falar o que aconteceu? [Discussão]

Taís: Vai falar um monte para a gente.

Nesse trecho é perceptível a existência de um conflito na relação professora-aluno, uma vez que, aparentemente, as crianças se sentem duplamente prejudicadas pela ação da educadora: no primeiro momento ela os confunde (ao escrever na lousa e apagá-la continuamente) e no segundo os julga negativamente, em virtude da própria desorganização.

Entre os alunos do Grupo 3, a avaliação não é sentida como uma via de mão dupla; para eles é preciso que a pessoa seja uma autoridade reconhecida para poder avaliar. Pais e professores estão autorizados a avaliar, já as crianças, especialmente as que não apresentam bom desempenho, não estão. Parece que esses alunos se sentem tão diminuídos - em razão dos resultados por eles obtidos - que não conseguem se perceber como produtores de significados.

Com tudo isso, pode-se inferir que enquanto para alunos dos Grupos 1 e 2 é possível defender-se dos olhares alheios - avaliando os avaliadores - para as crianças do Grupo 3 a avaliação escolar é implacável, pois a sensação de inferioridade é tanta que eles não se sentem autorizados a avaliar outras pessoas, principalmente quem eles consideram autoridade.

\section{ATÉ QUE PONTO A AVALIAÇÃO ESCOLAR É OBJETIVA? OS PROFESSORES COMO AVALIADORES}

Conversar sobre a posição e a subjetividade dos professores na análise de instrumentos de avaliação foi um dos temas que geraram mais polêmica, não apenas por eventuais reflexões provocadas nos entrevistados, mas também pela minha dificuldade em formular uma questão que permitisse às crianças compreender o que, efetivamente, eu queria conhecer. Imaginei conseguir respostas para essa questão, perguntando aos alunos se obteriam o mesmo resultado final em uma prova corrigida por pessoas diferentes. Em virtude da faixa etária dos entrevistados, para algumas crianças a suposição proposta foi considerada excessivamente abstrata, pouco objetiva e de difícil compreensão. Apesar disso, pela dinâmica experimentada em cada uma das entrevistas, conclui- 
se que a possibilidade de compreender essa suposição está fortemente relacionada ao desempenho escolar.

Por outro lado, todos os alunos são capazes de identificar, na atuação das professoras, minúcias que permitem a eles conhecê-las e estabelecer a melhor forma de se relacionar com elas - como mostram Helena e Ísis no trecho a seguir.

\section{Grupo 1}

Helena: Dependendo da tolerância da professora, as pessoas bagunçam mais ou menos. Na aula de Educação Física muita gente bagunça, mas a aula que eu acho que mais bagunçam é a de Música, talvez porque a professora seja mais tolerante. E a aula da Margarida é que menos bagunçam, porque na hora de dar bronca ela é brava mesmo! A da Carolina mais ou menos, ela tem uma tolerância média, depois de algum tempo ela dá uma bronca.

Ísis: Assim, né... Elas não dariam a mesma avaliação pelo comportamento, nunca! Outro dia, na sala da Carol eu estava conversando, ela viu e tudo bem... não falou nada, mas ai Margarida [que passava pelo corredor] viu e olhou para Carol, aí, né... a Carolina me deu uma bronca... Até fora da aula dela a Margarida pega no pé...

No que concerne à determinação dos resultados há uma certa relutância nas respostas das crianças, pois reconhecem as diferenças na forma e nos critérios de correção de cada uma das professoras, porém, têm dificuldade em admitir que essas desigualdades podem interferir na nota/conceito.

\section{Grupo 1}

Jade: Você até tiraria a mesma nota, mas cada uma corrige de um jeito, a Margarida pelos acertos, a Carolina pelos objetivos... não sei se tiraria a mesma nota, talvez não.

Helena: A Margarida corrige erro de ortografia não só quando o sentido muda, a Carol se você escreve uma palavra com SS no lugar de C ela dá meio certo, porque também não está correto.

Ísis: A professora tem um jeito diferente de corrigir, a Carolina, por exemplo, dá uma prova de cinco acertos de Matemática, mas exige bastante, a Margarida dá 50, lá para cima... Daí, eu acho que não seria o mesmo resultado. 


\section{Grupo 3}

Pesquisadora: [...] Vocês tirariam a mesma nota com a Margarida corrigindo e com a Carolina corrigindo?

Vários: Não/Sim.

Fernanda: Não, porque com a Margarida, ou com a Carol, a gente ia estudar bem menos, aí depois do recreio a gente podia estudar mais e, na outra prova, a gente ia saber mais...[...]

Pesquisadora: Deixe-me mudar o jeito de fazer a pergunta: ... o Pedro tem um irmão gêmeo, o Paulo, que é idêntico a ele: pensam as mesmas coisas, fazem as mesmas coisas. O Pedro tem aula com a Margarida e o Paulo com a Carolina... O Pedro e o Paulo tirariam a mesma nota?

Vários: Sim.

Pesquisadora: Sim? Por quê?

Fernanda: Não, porque um podia estudar mais do que o outro.

Edu: Mas ela disse que são idênticos; iam estudar igual.

Pesquisadora: É, os dois estudaram a mesma coisa.

Fernanda: Um podia decorar uma coisa, e o outro outra.

Pesquisadora: Os dois decoraram a mesma coisa: idêntico, idêntico.

Gabi: Os dois não podem ter a mesma inteligência...

Se compararmos as reflexões dos alunos dos Grupos 1 e 3, poderemos concluir que crianças com dificuldades de aprendizagem enxergam a avaliação como uma prática bem mais objetiva do que os alunos com bom desempenho As meninas do Grupo 1, que protagonizaram o diálogo sobre esse tema, não conseguem definir se o fato de duas professoras corrigirem a mesma prova mudaria os resultados finais; contudo, em nenhum momento, referem-se a si próprias como as responsáveis por essa possível diferença. As eventuais disparidades ocorrem, pois cada educadora atua de uma forma.

Os alunos do Grupo 3 também percebem as diferenças existentes nas práticas das duas professoras; entretanto, não conseguem responsabilizá-las por eventuais diferenças nos resultados. Segundo Fernanda, o fato de as professoras serem diferentes faz com que os alunos estudem mais ou menos. Ao falarmos sobre irmãos gêmeos, esses alunos não conseguiam imaginá-los como "idênticos", tiveram mais facilidade em refletir sobre a impossibilidade de isso acontecer do que sobre a possibilidade de eles terem resultados desiguais simplesmente porque a prova seria corrigida por pessoas diferentes. Ou seja, alunos do Grupo 3, de modo geral, responsabilizam exclusivamente a si próprios pelas diferenças nos resultados. Aparentemente, não percebem que os valores, as sensações e as emoções das professoras podem influenciar nos resultados finais. 


\section{PROFESSORA PREFERE ALUNO QUE VAI BEM?}

Durante praticamente todas as entrevistas, os alunos, mesmo não percebendo, avaliaram suas professoras, apontando suas características, adjetivando-as e explicitando as relações estabelecidas com eles; eventualmente, mostraram-se ressentidos com uma ou outra situação, mas só falaram claramente sobre as preferências das professoras, em relação a seus alunos, quando lhes perguntei: "As professoras preferem alunos que vão bem?"

As respostas obtidas assinalam que praticamente todos os alunos têm uma percepção similar em relação a essa questão. Parece claro para eles que Margarida e Carolina nutrem sentimentos e expectativas diferentes; além disso, reconhecem que o fato de terem preferência por determinados alunos não significa que deixem de proporcionar a aprendizagem de conteúdos escolares aos demais.

Os primeiros entrevistados, do Grupo 1, disseram que ambas tratam a todos igualmente; contudo, reconhecem que Carolina tem melhor convivência com alguns alunos. Gabi, do Grupo 3, percebe essa diferença de tratamento e mostra-se bastante ressentida.

\section{Grupo 3}

Gabi: Qualquer coisa, assim, é sempre: "Vai lá, fulano, fazer isso, vai lá. Por que não manda os outros?

Ana: Isso é verdade.

Juciele: Ela só fala com as pessoas que são melhores, só elas podem fazer as coisas.

No próximo trecho, com diálogos ocorridos no Grupo 1, os alunos apontam as diferenças de tratamento, justificam-nas e até absolvem a professora, como fez Vítor.

\section{Grupo 1}

Marcelo: Quem é assim... quem não tira nota boa ela não fala nada porque não tem tempo livre... a Carolina é mais intensa com a gente, a gente acaba e vai à mesa dela conversar, os outros não, porque eles não acabam... [...]

Vítor: É assim: se tiver um moleque milionário e outro classe média, de qual você vai ser amigo? [...]

Pesquisadora: Vamos voltar ao caso do aluno que tira nota boa ou ruim. O que os professores fazem para vocês perceberem que eles tratam diferente?

Débora: Na hora de entregar a prova: Olha, Parabéns! 
Daniel: Quando a gente levanta a mão: com quem a professora vai falar? Com você, que já sabe, pode ajudar; os outros ficam lá, de mão levantada.

Daiane: Ela te agrada mais.

Pesquisadora: Agrada mais, como?

Daiane: Você faz uma coisa direitinho, aí ela fala: Ah! Parabéns!

Débora: Para os outros é sempre assim: Você precisa melhorar, sabe? [...]

Vítor: Elas fazem uma brincadeira comigo... A Carol, quando a gente vai à mesa dela... ela mostra outra linha [referindo-se ao controle de conceitos das professoras] com NS, NS, NS, sem mostrar o nome, e depois mostra o meu: PS, PS, PS.

Daniel: É, a professora brinca mais com quem tira nota boa, não com quem tira nota ruim...

Débora: Ela só dá [devolve a prova] com desprezo: Olha, aí.

Daniel: Ela não pode fazer nenhuma cara, quando devolve a nossa ela faz: "Parabéns". Para os outros não faz nenhuma cara, ou brava...

De modo geral, alunos do Grupo 1 acreditam experimentar certas regalias que os outros não têm. Aliás, a existência de regalias para algumas crianças foi apontada por todos os grupos; porém, alguns alunos do Grupo 2 tiveram maiores dificuldades em concordar com os colegas. No diálogo anterior, os alunos explicam que crianças com bom desempenho têm mais oportunidades de conversar com as professoras, pois têm mais "tempo" para isso. No cotidiano escolar há pouco espaço para conversas informais e o que existe não é oferecido a todos; segundo os entrevistados, eles podem conversar com a professora se terminam a tarefa mais rapidamente do que as outras crianças, e isso, sem dúvida, relaciona-se à facilidade para resolvê-la. Desse modo, acaba institucionalizando-se que alunos com bom desempenho podem conversar com a professora.

Assim como os demais, os membros do Grupos 3 percebem as preferências das professoras. Gabi e Ana apontam isso de forma bastante enfática, e no diálogo a seguir podemos enxergar como isso as magoa. Por outro lado, elas concordam que Carolina se esforça para não expor os alunos e sempre procura ajudá-los a superar as dificuldades, tratando-os, quando necessário, de forma diferenciada.

\section{Grupo 3}

Pesquisadora: As professoras preferem alunos que só tiram PS?

Gabi: É, com certeza...

Ana: Não, ela gosta de todos, uns têm mais dificuldade, tipo assim... ela ajuda mais a estudar...[...]

Gabi: A Margarida não faz diferença de aluno, já a Carolina... ela faz um pouco. [...] Ela manda ir à lousa, fazer conta na lousa, quem tem mais dificuldade... 
porque as pessoas que não têm dificuldade, a Carolina já sabe que são legais... não, que já sabem. Mas os outros ela vê o que estão fazendo, é uma chance de aprender...

A maioria das crianças nota com mais clareza as preferências da professora Carolina, que busca aproximar-se delas; entretanto, nem todos se sentem incluídos nesse movimento. Por ser coordenadora da escola, à época da pesquisa, a interpretação dessas afirmações torna-se bastante complexa, pois me relacionava diariamente com as duas professoras e fui construindo significados sobre a atuação de cada uma delas. Assim, Carolina pareceu-me extremamente conscienciosa de suas obrigações profissionais, incluindo a busca por compreender as relações que estabelece com cada um de seus alunos. Tanto em conversas informais quanto em reuniões pedagógicas conversávamos sobre isso e, muitas vezes, ela explicitou suas preferências, nas quais encontramos alunos que não apresentam bom desempenho. De modo geral, as preferências de Carolina vão ao encontro das impressões de Helena, cuja fala transcrevo a seguir.

\section{Grupo 1}

Helena: A professora, não é que ela goste de todo mundo do mesmo jeito, mas também não é que ela não goste de uma pessoa; às vezes, ela simpatiza mais com uma pessoa, não só por causa do comportamento, às vezes pela pessoa que ela seja.

Considerando que a afirmação acima é verdadeira, podemos analisar o fato de os alunos relacionarem a preferência da professora com o bom desempenho escolar. Essa idéia, provavelmente, está pautada nas expectativas sociais sobre a questão: espera-se que os alunos tenham bom desempenho; então, crianças que cumprem essa expectativa são as mais queridas.

Margarida, por sua vez, é tida por todos como brava e exigente, o que a torna - aos olhos dos alunos - mais justa, pois a ninguém é permitido ir à mesa dela conversar. Nesse caso, a suposta preferência da professora é pautada pela organização da sala de aula e pela manutenção da ordem e do silêncio e não pelo desempenho. Segundo as crianças, Margarida implica com os alunos que atrapalham a aula, pois em vez de fazer alguma atividade ou ouvir suas explicações ficam conversando ou brincando. Outro aspecto que os alunos observam na professora Margarida é a sua exigência maior com crianças que não têm dificuldade para a aprendizagem dos conteúdos escolares e apresentam queda no desempenho. Segundo Daniele, ela já espera que determinados alunos não 
tenham bom desempenho; o que não significa que deixe de auxiliá-los ou oferecer-lhes atividades diferenciadas.

\section{Grupo 1}

Daniele: Nesse caso, assim, de nota não adianta muita coisa a Margarida pegar e falar... é engraçado... as pessoas que tiram NS... a Margarida já se acostumou com a idéia... quando é com a gente, sim, ela pega no pé. Por exemplo, uma pessoa que tira PS, PS, PS e, de repente, tira $S$, aí sim ela fala que piorou muito. As pessoas que sempre tiram NS ela nem fala muito.

De acordo com os sentidos produzidos pelos alunos, os critérios das professoras para determinar suas preferências são diferentes, mas eles acreditam que para conquistar esse espaço é preciso manter-se em determinado patamar de excelência, seja no desempenho, seja no comportamento.

\section{O IMPACTO DO DESEMPENHO ESCOLAR}

Pela análise dos dados, percebe-se que as representações dos alunos a respeito do impacto da avaliação para a vida deles variam, e muito, conforme seu desempenho escolar. No decorrer das entrevistas, essa questão apareceu com bastante intensidade; em alguns momentos diretamente e em outros nas entrelinhas dos discursos infantis.

Perguntei aos entrevistados se os conceitos obtidos na escola interferem nas relações familiares, depois conversamos a respeito de suas conseqüências para o estabelecimento de amizades e da sua intervenção para a garantia de sucesso profissional. Há alguma relação entre o conceito/a nota que vocês tiram no boletim e o que acontece em casa? Ao apresentar essa questão, imaginei que para alunos com bom desempenho o impacto seria bastante positivo, uma vez que perceberiam o reconhecimento de seus pais. Não obstante, para a maioria das crianças, a sensação apreendida relacionase fortemente às expectativas não cumpridas e às cobranças de melhoria de desempenho. Marcelo, que é considerado pelos colegas um dos caras mais inteligentes, diz que não pode ficar desatento, pois seu pai costuma tomar os temas discutidos em classe. Para Débora, sua mãe é ainda mais enfática, pois a lembra que tem capacidade para ser primeira da classe.

Aparentemente, os pais cobram avanços no desempenho desses alunos, porque os julgam capazes, e de alguma forma isso os estimula a continuar ocupando essas posições. Situação parecida é vivida por alunos do Grupo 2, apesar de alguns pais se mostrarem aborrecidos quando seus 
filhos não conseguem desempenho satisfatório, como esclarecem José e Bruno.

\section{Grupo 2}

Pesquisadora: Vocês acham que as provas, o boletim fazem diferença para a avaliação que seus pais fazem de vocês?

José: Nossa, como faz!

Bruna: Quando eu tiro PS minha mãe fica toda feliz: Ai, minha filhinha..., mas se eu tiro NS ela: Ai, Bruna, você tem que estudar mais... assim não é possível...

José: Quando eu tiro PS minha mãe, quando vai assinar a prova, faz uma carinha do lado dizendo que ficou feliz, quando eu tiro NS ela faz uma carinha chorando...

Entre os alunos do Grupo 3, o impacto é sentido de forma bastante incisiva; muitas crianças mostram que os pais não se sentem orgulhosos de seus desempenhos e, mais do que isso, a incapacidade deles é enfatizada. Everton e André foram especialmente claros no que se refere às representações dos pais em relação ao seu desenvolvimento cognitivo.

\section{Grupo 3}

Everton: Minha mãe fala que estão faltando uns preguinhos na minha cabeça.

André: Na minha não está faltando um, está faltando um monte... Minha mãe fala que na minha cabeça está faltando parafuso e na do Artur [irmão] não está faltando nenhum.

Praticamente todos os alunos sentem uma cobrança dos pais em relação ao desempenho escolar; contudo, o impacto desses sentimentos para a construção do valor de si é bastante diferente em cada criança e tem forte ligação com os resultados obtidos.

Ter um bom rendimento escolar, segundo os alunos, é a principal preocupação dos pais em relação à escolaridade dos filhos. Perguntei a eles o que seria pior: levar uma prova com NS ou um bilhete informando que haviam sido mal educados com a professora. Praticamente todas as crianças disseram que o bilhete não teria tanta importância e justificaram isso pela quantidade de vezes em que ocorreria; também disseram que o aluno tem condições de não fazer mais isso, enquanto melhorar o desempenho não seria tão simples.

A correlação entre a avaliação escolar e a cobrança que aparece nos efeitos das avaliações escolares para as relações familiares pode ser positiva - quando os alunos se sentem incentivados a aprender os conteúdos e apresentam condições para isso - ou negativa - quando as crianças não se 
sentem capacitadas para oferecer a moeda de troca - o que não apenas as paralisa como também produz os ingredientes necessários para a construção de uma representação de si negativa, que, como vimos, acaba dificultando a aprendizagem, entre outras conseqüências, como acontece com Everton.

\section{Grupo 3}

Everton: Quase todos os NS que eu tiro, né? Minha mãe não deixa eu sair para rua, daí ela pega e deixa eu fazer a lição no caderno; se eu fizer certo tudo bem, se eu errar ela bate, bate, bate... Meu pai uma vez: "Everton, eu vou passar uma lição para você e você vai ter que acertar..." Aí eu errei, né? "Everton, fica mais esperto! $P a ́, p a ́, p a ́$ " [fazendo gestos como se estivesse batendo].

Os resultados obtidos nas avaliações não influenciam apenas as relações familiares, mas também as amizades que se estabelecem nas salas de aula. Aos alunos do Grupo 1 perguntei se preferiam ter amigos que só tiravam PS. Praticamente todos disseram que esse não seria um critério na hora de definir as amizades. Na seqüência, solicitei que me dissessem quem eram seus melhores amigos, e quase todos (exceto quatro, dos vinte entrevistados desse grupo) confirmaram preferir brincar e conversar com crianças pertencentes ao grupo de alunos com bom desempenho escolar.

Segundo Roberta e Daniele (Grupo 1), é preciso cuidado na hora de escolher as amizades para não prejudicar o espaço já adquirido perante a professora, conforme ilustrado a seguir:

\section{Grupo 1}

Roberta: Nessa história de avaliação eu percebi que o nosso melhor amigo não conversa com a gente na sala de aula; por exemplo, eu estou numa prova do lado dela, ela vem pedir para colar, perguntar alguma coisa que não sabe, isso não é um amigo verdadeiro...

Daniele: É um amigo interesseiro...

Roberta: Na hora em que o professor vai brigar, ele briga com você, porque você está dando trela.

É interessante observar que essas crianças realmente se sentem diferenciadas em relação aos colegas, pois não competem com alunos que apresentam baixo desempenho e até procuram ajudá-los, batendo palmas ou parabenizando-os quando percebem um avanço na aprendizagem e indignando-se com a professora por julgarem que ela não os incentiva adequadamente. Parece que os alunos do Grupo 1 se consideram tão 
privilegiados que, efetivamente, não pertencem à mesma categoria dos alunos do Grupo 3, portanto, não se sentem ameaçados por eles.

Por outro lado, os alunos do Grupo 1 precisam manter o espaço que conquistaram; assim, todo o processo avaliativo vivido por eles torna-se também bastante pesado, uma vez que precisam ter o sucesso sempre confirmado, não há espaço para eventuais fracassos. Para esse grupo, a definição de sucesso e de fracasso é bastante diferente da experimentada por alunos do Grupo 3: enquanto estes contentam-se ao atingir os mínimos objetivos de ensino propostos pelas professoras ou pela instituição, aqueles buscam a excelência, a perfeição.

Os alunos dos Grupos 2 e 3, ao contrário dos do Grupo 1, não utilizam o desempenho escolar como critério na escolha dos amigos; além disso, a possibilidade de a amizade auxiliá-los na melhoria do desempenho escolar aparece com ênfase, como mostram Ana e Bruna.

\section{Grupo 2}

Pesquisadora: Faz alguma diferença ter amigo que tira PS ou NS?

Ana: Faz diferença sim... se a Bruna tirou PS e eu NS ela vai poder dar dicas para a próxima prova.

Bruna: Mas é a única diferença... eu acho...

No final das entrevistas, conversamos sobre a relação entre ter bom desempenho escolar e obter sucesso profissional. As respostas obtidas em cada um dos grupos foram muito diferentes, mas todos reconhecem a existência de celebridades que não freqüentaram a escola ou o fizeram por pouco tempo. Assim, não enxergam o desempenho escolar como determinante, embora, entre os alunos do Grupo 1, sua influência seja reconhecida, tendendo a ser necessária. Segundo essas crianças, o relevante não é exatamente a nota, mas sim a aprendizagem; é ter o conhecimento formal, adquirido na escola. Entre os alunos do Grupo 2, as respostas esclarecem que a escolaridade não determina o sucesso profissional, contudo enfatizam que, em algum momento, a pessoa terá que mostrar seu esforço, terá que ralar.

Segundo certos alunos dos Grupos 2 e 3, avaliar é uma forma de medir o QI, a inteligência e a esperteza. Essas três são características estáveis; uma pessoa é inteligente, é esperta e tem determinado nível de QI. Em outras palavras, avalia-se como a pessoa é e não como está seu processo de aprendizagem de determinado conteúdo, e isso nos mostra que o caráter determinante da avaliação está presente nos sentidos produzidos pelos alunos. 
Para alguns entrevistados do Grupo 3, essa sensação é acentuada; segundo Alex, trata-se de um documento que irá durar para o resto da vida. De modo geral, essas crianças percebem a existência de inúmeras razões que justificariam suas dificuldades para a aprendizagem dos conteúdos escolares; mas responsabilizam-se por isso, como se fosse uma característica inerente a elas, imutável e previamente determinada. Dessa forma, o fracasso escolar - ou o baixo desempenho - aparece como algo exclusivamente intrínseco e não como resultado da complexa interação entre fatores internos e externos.

\section{7 “QUEM VAI MAL NA ESCOLA É BURRO?” COMO OS ALUNOS JUSTIFICAM O DESEMPENHO ESCOLAR}

Nos discursos de pais e de professores é possível encontrarmos recomendações para que os alunos estudem, prestem atenção nas aulas e fiquem atentos ao ler as fichas ou os livros didáticos. As crianças costumam repetir o que ouvem; talvez por isso, os alunos do Grupo 1 dizem que as diferenças de desempenho acontecem, em razão do esforço individual e da adequação de comportamento na sala de aula.

\section{Grupo 1}

Daniele: Sobre a gente passar de ano, eu acho assim: depende de cada aluno. Não tem que estudar só quando a professora passa a prova, não precisa esperar a professora falar, a gente já vai estudando em casa. [...]

Roberta: Quando eu chego em casa eu vou revendo tudo o que aprendi, a gente tem que estudar não apenas em dia de prova, mas no dia-a-dia. [...]

Daniele: Tipo assim: em provas de Matemática... a professora passa um problema, é falta até de memorizar... quem vai bem está mais interessado, pergunta. Muita gente tem vergonha de tirar dúvida. A professora pergunta: "Quem tem dúvida?" Aí, ninguém levanta a mão. Aí, a professora passa um exercício e a pessoa erra; que dizer... Por que na hora ela não fala se estava com dúvida?

Pesquisadora: E por que as pessoas têm vergonha?

Helena: De falar para a classe inteira que tem dificuldade, ser chamada de bobão. Todo mundo presta atenção no que deixa a pessoa para baixo, para depois poder zoar com ela.

Daniele: A gente que vai bem... é porque eu não tenho vergonha de chegar e tirar a dúvida, entendeu? Às vezes não falo alto, mas depois vou lá e pergunto só para a professora.

Pesquisadora: Você acha que não tem vergonha porque na maioria das vezes você vai bem? 
Daniele: Quando eu tenho vergonha de perguntar... eu não lembrava o que é adjetivo, aí eu fico com a dúvida..., chego em casa e pergunto: mãe, o que é adjetivo? Aí, eu resolvo...

No decorrer da conversa, essas crianças ampliaram a visão que tinham sobre o que explicaria o desempenho escolar, mas isso não significa que tenham chegado a um consenso. Contudo, conseguiram enxergar outras razões além da falta de interesse, de esforço ou de adequação de atitude. Nesse trecho, fica claro que nem os bons alunos se comportam, sempre, conforme as atitudes supostamente esperadas pelos professores e pais. Daniele, por exemplo, aponta que seus colegas não apresentam bom desempenho, porque não tiram suas dúvidas com as professoras; porém, ela acaba contando que também não faz isso, prefere perguntar em casa, longe dos olhares dos colegas.

Apesar de viverem uma situação diferente da dos alunos do Grupo 1, as crianças do Grupo 2 apresentam muitas respostas similares às deles. Num primeiro momento, todos dizem que a diferença de desempenho está no envolvimento individual; entretanto, surgiram explicações que não foram ditas pelas crianças do Grupo 1: excessiva dificuldade para manter a concentração e necessidade de mais tempo para a aprendizagem; além disso, o nervosismo aparece como um fator determinante.

Os alunos do Grupo 3 também iniciaram as explicações sobre as diferenças de desempenho pela falta de envolvimento individual. Todavia, ao falarmos sobre isso, mostraram-se mais ressentidos e emocionados do que os entrevistados anteriores. Essas crianças sabem que a melhoria de desempenho, muitas vezes, independe do interesse e do esforço. Em outras palavras, reconhecem que nem sempre são capazes de controlar suas ações e sentimentos - apesar de se enxergarem como responsáveis pelos resultados obtidos. Alguns entrevistados atribuem ao nervosismo, causado pelo medo das provas, um possível prejuízo de desempenho.

\section{Grupo 3}

Pesquisadora: Por que tem aluno que estuda, se esforça muito e tira NS?

Clara: Fica nervoso.

Edu: Fica distraído.

Josué: Está estudando e fica pensando: vou tirar NS, vou tirar NS, vou tirar NS...

Alex: Não confia nele mesmo. [...]

Clara: Mesmo antes de fazer a prova, em casa, eu fico pensando...

Pesquisadora: Muito antes de fazer a prova... já estuda pensando na nota?

Vários: É. 
Pesquisadora: E quando estuda pensando na nota, é melhor ou pior do que estudar sem pensar na nota?

Alex: É pior.

Edu: Você estuda bastante, acaba se distraindo pensando na nota e acaba não estudando. [...]

Clara: A pessoa não confia em si mesma, já estuda pensando nisso e acaba prejudicando[-se] nas notas.

Josué: Quando vou estudar, ficou muito, muito nervoso, pensando na nota, aí eu falo: vou jogar alguma coisa para me distrair, aí acabo não estudando...

No diálogo acima, Clara e seus colegas explicitam como a relação entre a construção do valor de si e a aprendizagem de conteúdos escolares, incluindo aí o desempenho e os resultados finais, é intensa. Quem estuda sem confiar em si mesmo acaba indo mal... e quem costuma ir mal deixa de confiar em si, e acaba não estudando, como explicou Josué.

Esses alunos sabem que não há uma relação direta entre seguir as prescrições e o resultado obtido; porém, relutam em apresentar suas conclusões, até porque isso não minimizaria suas culpas, seus sentimentos de responsabilidade.

De modo geral, as crianças evitam qualificar os colegas como burros, procuram justificar o baixo desempenho escolar pela falta de esforço, de interesse e, além disso, conseguem fazer uma diferenciação entre ter dificuldade para a aprendizagem de conteúdos escolares e não ter inteligência, capacidade de aprender. Os alunos dos Grupos 1 e 2 disseram que as crianças com dificuldades conseguem aprender algumas coisas, enquanto quem é burro não aprende nada. Para os alunos do Grupo 3 essa diferenciação não é tão tranqüila, eles precisaram rever emoções e sensações e, juntos, atribuir novos significados aos sentidos já construídos para concluir que ter dificuldade para aprendizagem dos conteúdos escolares não é sinônimo de falta de inteligência.

Em praticamente todos os trechos das entrevistas apresentados até aqui, pode-se observar uma conexão circular entre a aprendizagem dos conteúdos escolares e a construção do valor de si. Por isso, o sentido do valor de si construído nessa relação é difícil de ser modificado, pois se estabelece por um movimento em que o percurso está previamente determinado. 


\section{NAS PRÁTICAS DISCURSIVAS DOS ALUNOS, OS DISCURSOS DAS PROFESSORAS}

Durante as entrevistas, vários foram os momentos em que os alunos se referiram, diretamente ou não, aos discursos e/ou às práticas discursivas de seus professores - mesmo sem ter consciência desse processo. Assim, as práticas discursivas dos alunos tornaram possível o desvelamento dos discursos de Carolina e de Margarida.

Em alguns momentos, as professoras têm bastante clareza dos significados e objetivos de suas ações e atuam em consonância com determinadas concepções teóricas; quando isso ocorre, enxergamos nas práticas discursivas dos alunos uma relação extremamente nítida entre a ação da educadora e o discurso teórico.

Entretanto, há situações em que encontramos apenas fragmentos de concepções teóricas, e esses, ao se tornarem vozes presentes nas práticas discursivas dos alunos, aparecem debatendo-se com os discursos que os originaram. Como na brincadeira de telefone sem fio, na qual as pessoas falam o que entenderam, sem grande preocupação com os sentidos produzidos por quem iniciou o passatempo.

Por exemplo, no começo das entrevistas, praticamente todos os alunos disseram associar a palavra avaliação à prova escrita. Desde o início dos anos 1980, no Brasil, os educadores têm tentado identificar a avaliação como uma parte do processo de favorecimento da aprendizagem. De modo geral, os professores buscam opor-se a um modelo de avaliação que consistia em transmitir, verificar e simplesmente registrar a aprendizagem dos alunos, quantificando-a. Entre outras coisas, procurou-se desmistificar os momentos de verificação da aprendizagem, tornando-os parte do processo de ensino.

Nesse sentido, os educadores tomaram medidas para minimizar a tensão causada durante a verificação da aprendizagem: elaboraram provas mais curtas, mais freqüentes e evitaram ritualizar essas situações. Entre outras coisas, a palavra prova foi substituída pela palavra avaliação.

Dessa forma, é bastante provável que os alunos entrevistados tenham identificado a palavra avaliação com a prova escrita, porque é assim que é chamada pelos professores. O que não significa que esse seja o único sentido percebido pelos alunos, pois em poucos segundos eles apresentaram outros significados para a avaliação. Vale esclarecer que o fato de substituir o nome dado a esse instrumento de verificação de aprendizagem não garante que ela tenha sido revista, daí a idéia de termos fragmentos, no caso dispersos, de discursos a respeito de práticas avaliativas. 
As mudanças vividas nos últimos anos, relacionadas às práticas avaliativas, estão diretamente ligadas a uma resignificação da compreensão do processo de ensino e de aprendizagem, pois se buscava (e busca-se) o desenvolvimento de uma ação reflexiva por parte do educador, tendo como objetivo rever estratégias de ensino para otimizar as aprendizagens. Vimos que uma das mudanças práticas foi garantir maior número de instrumentos de avaliação que deveriam ser utilizados durante o percurso de aprendizagem de determinado conteúdo e não apenas ao final de certo período. Em outras palavras, a avaliação deveria ser contínua e processual - para que o professor conhecesse o processo de aprendizagem dos seus alunos, verificando, com isso, se era necessário rever as estratégias de ensino.

O professor poderia destacar do cotidiano escolar algumas atividades e situações para utilizá-las como instrumentos de avaliação formal; assim, a avaliação deveria pautar-se por momentos freqüentes, porém pontuais. No entanto, para os alunos, isso significou que tudo passou a valer nota. Ou seja, alguns professores ajustaram o discurso às necessidades pessoais de manutenção do controle, mesmo que não tivessem a intenção de fazer isso. Desse modo, foi possível garantir a ordem da sala de aula, uma vez que os alunos estariam sendo formalmente avaliados o tempo todo; então, qualquer situação escolar tornou-se um instrumento legítimo e institucionalizado de avaliação da aprendizagem.

No discurso dos professores, os alunos estão sempre sendo avaliados - o que é verdade do ponto de vista subjetivo -; contudo, quando efetivamente se colocam no lugar de avaliadores, os educadores definem com bastante clareza quais devem ser os instrumentos e os critérios utilizados. Com o intuito de manter o controle sobre as atitudes dos alunos e a ordem da sala de aula, alguns professores evitam esclarecer essas diferenças.

Nesse sentido, a relação estabelecida com os alunos torna-se bastante dúbia: eles afirmam que são avaliados o tempo todo e sentem isso de várias formas - por exemplo, pelo olhar das professoras. Ao mesmo tempo, algumas crianças desconfiam que os conceitos por elas obtidos não refletem todos os momentos vividos, apenas situações específicas, especialmente os alunos do Grupo 1. Por isso, pode-se deduzir que a acuidade para perceber a incoerência entre o discurso do professor e a prática avaliativa está diretamente relacionada ao desempenho escolar.

Quando os entrevistados comentam as diferenças existentes entre as formas de avaliação de cada uma das professoras, encontramos discursos que refletem concepções teóricas diferenciadas. $\mathrm{O}$ fato de os alunos explicarem, com surpreendente nitidez, como se dão essas diferenças, leva- 
nos a acreditar que esse é um assunto debatido na sala de aula pelas duas professoras.

Novamente, vemos certa incoerência nessa atitude, pois, ao mesmo tempo em que não definem para os alunos os momentos em que estão sendo avaliados formalmente, Margarida e Carolina são claras em relação aos seus critérios de avaliação. Mediante as práticas discursivas dos entrevistados, pode-se reconstituir as práticas avaliativas de cada professor e inferir sobre as concepções subjacentes. Vale esclarecer que o fato de ser coordenadora da escola influi nessa análise, pois também construí minhas representações a respeito das práticas de cada uma delas.

Segundo as crianças, Carolina parte de seus objetivos de ensino para analisar as atividades, observando até que ponto eles foram atingidos. A idéia de avaliação por objetivos pode estar relacionada a dois autores muito difundidos no Brasil, que apresentam visões bastante diferentes do processo de ensino e de aprendizagem: Ralph Tyler e Cipriano Carlos Luckesi.

Levando em conta o relato dos alunos sobre o trabalho desenvolvido por Carolina, posso afirmar que suas idéias a respeito da avaliação escolar convergem com as construídas por Luckesi (1990). Para esse autor, ao avaliar deve-se estabelecer um padrão mínimo de conhecimentos, habilidades e hábitos que o educando deverá adquirir. Esse padrão é definido com base nas características do grupo-classe e em consonância com as reflexões construídas pelo grupo de professores da instituição. Isso pode ser compreendido como os objetivos de ensino dos quais a professora parte. Na seqüência, Carolina observa, nas provas dos alunos, até que ponto esses objetivos foram atingidos e solicita aos alunos que revejam sua aprendizagem, o que também é sugerido por Luckesi.

Além disso, ela costuma propor - conforme relato das crianças provas freqüentes e relativamente curtas, que apresentam objetivos pontuais, numa clara alusão à avaliação contínua e processual, nesse caso vista sob um ângulo mais próximo da idéia original.

Margarida também explicita para os educandos os critérios que utiliza para analisar as provas: ela identifica a quantidade exata de respostas que as crianças devem escrever e compara os resultados individuais a padrões de excelência - que seriam atingidos se todas as respostas estivessem corretas.

Podemos identificar essa prática de Margarida com as teorias de mensuração da aprendizagem desenvolvidas por Ralph Tyler nos Estados Unidos, na primeira metade do século $X X$, e que se desenvolveram no Brasil até meados dos anos 1970. Na ocasião, a avaliação da aprendizagem relacionava-se intensamente às técnicas de elaboração de instrumentos de 
mensuração, classificação, seleção e quantificação, com o objetivo de determinar padrões de excelência que deveriam ser seguidos pelos alunos.

Para Tyler, o objetivo da avaliação escolar é apreciar o grau de satisfação dos resultados obtidos em relação aos esperados; trata-se de uma medida desses resultados. Nessa concepção, não há uma preocupação com a problematização, com a revisão e com a contextualização dos objetivos de ensino, eles são definidos de acordo com critérios essencialmente técnicos.

Conforme atestaram diferentes alunos, a professora Margarida elabora provas que abrangem todos os conteúdos ensinados - e fora da ordem em que foram trabalhados em sala de aula. Além disso, em comparação com as da professora Carolina, suas avaliações são bastante longas e menos freqüentes. Com essa informação pode-se deduzir que para Margarida a idéia de avaliação contínua refere-se efetivamente à manutenção do controle na sala de aula.

Carolina e Margarida trabalham na mesma instituição onde há espaço para reflexões conjuntas, aprimoramento das ações e desenvolvimento de parâmetros a respeito do sistema de avaliação; ambas são consideradas bastante competentes e buscam rever práticas experimentadas na sala de aula. Assim, por que suas concepções sobre avaliação escolar são tão diferentes? $\mathrm{Na}$ verdade, não há uma única resposta possível para essa pergunta, pois inúmeros fatores interferem na atuação dos educadores, mas suas vivências, como alunas, podem ter determinado suas práticas.

Se considerarmos as experiências individuais - um conjunto de esquemas apreendidos e atualizados desde a infância, nas quais a memória está presente traduzida em afetos -, veremos que é nesse tempo - no tempo vivido - que ocorre a aprendizagem das linguagens sociais. É nele que enraizamos nossas narrativas pessoais e nossa identidade, e as reminiscências de suas vozes povoam nossas práticas discursivas. Enquanto as concepções teóricas apreendidas pelos professores referem-se ao tempo longo - presente em suas práticas discursivas - as lembranças afetivas determinam o tempo vivido, e ambos misturam-se no tempo curto, traduzido em práticas discursivas que passarão a compor os sentidos produzidos por seus alunos. Em outras palavras: as professoras revivem, com seus alunos, as sensações que experimentaram no tempo em que eram estudantes.

Neste texto, vimos que os sentidos atribuídos à avaliação são inúmeros e relacionam-se à posição da pessoa que os produz. A escola é uma das instituições em que a avaliação aparece com muita força, pois é formalizada e parte intrínseca de seu cotidiano. Em muitas instituições, os professores debatem o sistema de avaliação, procurando definir se os 
conceitos ou as notas são os mais adequados para demonstrar o desempenho dos alunos; além disso, há uma enorme busca pelo estabelecimento de critérios objetivos e comuns para a avaliação. Essas ações são essenciais e devem ser valorizadas; todavia, é preciso que junto a elas haja um esforço para compreender como se dão as relações entre professores e alunos e entre alunos e alunos.

Os professores poderiam procurar identificar, em suas práticas, a origem de algumas das vozes presentes em seus discursos para perceberem até que ponto elas se referem ao tempo longo, ao curto, ou ao vivido; assim, terão mais chances de transformar suas práticas discursivas e, conseqüentemente, rever a qualidade da relação que estabelecem com seus alunos. É necessário também reconhecer os sentimentos, as emoções e sensações que permeiam as relações estabelecidas com cada aluno, pois esse desvelamento possibilita ao educador resignificar suas representações acerca de seus alunos e, com isso, modificar sua prática perante aquela criança, ampliando as possibilidades individuais de aprendizagem e, conseqüentemente, da construção de um valor de si positivo.

\section{REFERÊNCIAS BIBLIOGRÁFICAS}

ANDRÉ, Marli Eliza Dalmazo Afonso de. Etnografia da prática escolar. Campinas, SP: Papirus, 1995.

. Pesquisa em educação: buscando rigor e qualidade. Cadernos de Pesquisa. São Paulo, n.113, p. 51-64, jul. 2001.

AZANHA, José Mario Pires. Uma idéia de pesquisa educacional. São Paulo: Edusp,1992.

BAKHTIN, Mikhail. Estética da criação verbal. 2. ed. São Paulo: Martins Fontes, 1997. (Coleção Ensino Superior)

Marxismo e Filosofia da Linguagem. 8. ed. São Paulo: Hucitec, 1997.

BRAIT, Beth. Bakhtin, dialogismo e construção do sentido. Campinas, SP: Editora da Unicamp, 1997.

DEMO, Pedro; LA TAILLE, Yves de; HOFFMANN, Jussara. Grandes pensadores em educação: o desafio da aprendizagem, da formação moral e da avaliação. Porto Alegre, RS: Mediação, 2001. 
DIETZSCH, Mary Julia Martins. Espaços da linguagem da educação. São Paulo: Humanitas/FFLCH/USP, 1999.

FRANCO, Maria Laura Barbosa; ANDRÉ, Marli D. A. et al. Mesa-redonda: avaliação escolar. Cadernos de Pesquisa. São Paulo, n.74, p. 62-79, ago. 1990.

FREITAS, Luiz Carlos de. (org.) Avaliação: construindo o campo e a crítica. Florianópolis: Insular, 2002. . (org.) Questões de avaliação educacional. São Paulo: Komedi, 2003.

GALVÃO, Izabel. Cenas do cotidiano escolar: conflito sim, violência não. Petrópolis, RJ: Vozes, 2004.

GATTI, Bernardete A. Avaliação educacional no Brasil: experiências, problemas, recomendações. Estudos em Avaliação Educacional. São Paulo, n.10, p. 67-80, jul./dez. 1994.

HARKOT-DE-LA-TAILLE, Elizabeth. Ação moral e estereótipos culturais. In: ARANTES, Valéria Amorim. Afetividade na escola: alternativas teóricas e práticas. São Paulo: Summus, 2003.

KRAMER, Sonia. Autoria e autorização: questões éticas da pesquisa com crianças. Cadernos de Pesquisa. São Paulo, n.116, p. 41-59, jul. 2002.

LA TAILLE, Yves de. Desenvolvimento moral: princípios, sentimentos, valores. São Paulo: ATTA, Mídia e Educação. (Série Encontros) - vídeo.

. Vergonha, a ferida moral. Petrópolis, RJ: Vozes, 2002.

LEFEBVRE, Henri. La presencia y la ausência: contribuicion a la teoria de las representaciones. México: Fondo de Cultura Económica, 1993.

LUCKESI, Cipriano Carlos. Avaliação da aprendizagem escolar. São Paulo: Cortez, 2002.

Verificação ou avaliação: o que pratica a escola? Idéias 8. São Paulo: FDE, 1990. 
LÜDKE, Menga; MEDIANO, Zélia. (orgs.) Avaliação na escola de $1^{\circ}$ grau: uma análise sociológica. Campinas, SP: Papirus, 1992. (Coleção Magistério. Formação e trabalho pedagógico)

PATTO, Maria Helena Souza. A Produção do fracasso escolar: histórias de submissão e rebeldia. São Paulo: Casa do Psicólogo, 1999.

PENIN, Sonia Teresinha de Souza. Qualidade de ensino e progressão continuada. In: KRASILCHIK, Myrian. (org.) USP Fala sobre Educação. São Paulo: Feusp, 2002.

PERRENOUD, Philippe. Avaliação: da excelência à regulação das aprendizagens - entre duas lógicas. Porto Alegre, RS: Artes Médicas, 1999.

PIAGET, Jean. O Juízo moral na criança. São Paulo: Summus, 1994.

Fontes, 1993.

A Linguagem e o pensamento da criança. 6. ed. São Paulo: Martins

PINHEIRO, Odette de G. Entrevista: uma prática discursiva. In: SPINK, Mary Jane. (org.) Práticas discursivas e produção de sentidos no cotidiano: aproximações teóricas e metodológicas. São Paulo: Cortez, 2000.

SOUSA, Clarilza Prado de. (org.) Avaliação do rendimento escolar. Campinas, SP: Papirus, 1991. (Coleção Magistério: Formação e trabalho pedagógico)

SOUSA, Sandra Maria Zákia Lian. Avaliação escolar e democratização: o direito de errar. In: AQUINO, Julio Roberto Groppa. Erro e fracasso na escola. São Paulo: Summus, 1997.

A Avaliação na organização do ensino em ciclos. In: KRASILCHIK, Myrian. (org.) USP Fala Sobre Educação. São Paulo: Feusp, 2002.

SPINK, Mary Jane. (org.) Práticas discursivas e produção de sentidos no cotidiano: aproximações teóricas e metodológicas. São Paulo: Cortez, 2000.

VELHO, Gilberto. Individualismo e cultura: notas para uma antropologia da sociedade contemporânea. Rio de Janeiro: Jorge Zahar, 1987. 
VIANNA, Heraldo Marelim. Avaliação do rendimento escolar e a interação aluno/professor. Estudos em Avaliação Educacional. São Paulo, n. 7, p. 89-94, jan./jun. 1993.

Recebido em: setembro 2005

Aprovado para publicação em: novembro 2005 